\title{
África do Sul, nação-mulher: gênero e narrativa em Mhudi, de Sol Plaatje (1930)*
}

Raquel Gryszczenko Alves Gomes**

\section{Resumo}

Atentando para a narrativa de Mhudi - An Epic of South African Native Life a Hundred Years Ago, publicado em 1930 pelo político e jornalista sul-africano Sol Plaatje, analiso como os impactos das políticas segregacionistas que se intensificaram após a consolidação da União Sul Africana, em 1910, entrelaçam-se a aspectos fundamentais desse romance histórico. Na construção de sua personagem principal, Mhudi, Plaatje projeta não apenas um protagonismo feminino negro desejado para a nação sul-africana, mas também retoma aspectos da memória política sul-africana na tentativa de tecer novas possibilidades para as relações raciais naquele país.

Palavras-chave: Literatura, Gênero, África do Sul, Políticas Editoriais.

* Recebido para publicação em 30 de agosto de 2016, aceito em 6 de março de 2017.

** Pós-Doutoranda PNPD/Capes no Departamento de História da Universidade Estadual de Campinas, Campinas, SP, Brasil. raquel8755@gmail.com 
South Africa, A Female Nation: Gender and Narrative in Sol Plaatje's Mhudi (1930)

\begin{abstract}
This paper analyses aspects of the historical novel Mhudi - An Epic of South African Native Life a Hundred Years Ago, published by Sol Plaatje in 1930, that are related to the impacts of the segregational policies intensified after the establishment of the South African Union in 1910. In his novel, the South African politician and journalist presents his main character, Mhudi, as a desired model to the black female protagonism in South Africa, also exploring aspects of the South African political memory in an attempt to suggest new possibilities for race relations in that country.
\end{abstract}

Keywords: Literature, Gender, South Africa, Publishing Policies. 
Georgiana Margaret Solomon - inglesa frequentadora do círculo intelectual sul-africano que reunia políticos, jornalistas $e$ literatos questionadores da ação imperialista britânica no sul da África, alinhando-se com o projeto de uma nação mais inclusiva recebeu, em maio de 1930, uma carta de seu amigo Sol Plaatje: "Após dez anos de decepção, finalmente tive sucesso na publicação de meu livro. Lovedale irá publicá-lo. As provas devem chegar em algum dia dessa semana" (Plaatje apud Willan, 1984:349). ${ }^{1}$ Naquele ano, a Lovedale Press, editora da missão cristã de Lovedale estabelecida na região do Cabo em inícios do século XIX, aceitara publicar Mhudi - An Epic of South African Native Life a Hundred Years Ago, obra definida por seu autor como um romance histórico, com uma narrativa centrada no protagonismo estabelecido por uma mulher negra sul-africana. Nas décadas anteriores, Plaatje havia consolidado seu envolvimento na política africana contestadora da expansão de uma legislação segregacionista que, a partir da unificação do território, em 1910, ganhava cada vez mais força. Apesar de Plaatje ter se tornado uma referência política, é curioso pensar na dificuldade de fazer circular sua produção - dez anos separavam a publicação de Mhudi de sua finalização, em 1920. O que havia tornado possível a publicação do romance no ano de 1930? O que a Lovedale Press, editora até então reconhecida apenas pela publicação de livros e panfletos destinados à evangelização, vira em Mhudi - ao contrário de tantas outras editoras às quais Plaatje havia submetido seu texto? Para que essas e outras perguntas sejam respondidas, faz-se necessário um aprofundamento na trajetória de Sol Plaatje e também na narrativa apresentada em seu romance histórico.

\footnotetext{
1 Georgina Solomon (1845-1933) esposa de Saul Solomon, político reconhecido por sua defesa da chamada "causa nativa" no território sul-africano, foi assídua correspondente da escritora Olive Schreiner - importante influência na obra de Sol Plaatje, como veremos em páginas seguintes. Foi co-fundadora da South African Wome's Federation, em 1904 - organização criada para oferecer amparo às mulheres que enfrentavam a miséria após o final da Guerra Sul Africana (1899-1902).
} 
1. Sol Plaatje e a política das palavras

A biografia de Solomon Tshekisho Plaatje guarda muitos dos aspectos que marcaram a constituição $e$ a consolidação de um primeiro grupo sul-africano de políticos negros articulados em torno da reivindicação de seu espaço no estado nacional criado, em 1910, sob o nome de União Sul Africana - uma geração chamada de "proto-nacionalista" (Boehmer, 2002:134), fortemente permeada pela educação missionária e pela experiência de trânsito por múltiplas influências culturais. Barolong de origem tswana, ${ }^{2}$ nasceu em 1876, no distrito de Boshof, no Estado Livre de Orange - o sexto dos oito filhos de Martha e Johannes Plaatje. Registros biográficos, apesar de escassos, dão conta de que o primeiro tswana da familia Plaatje a converter-se ao cristianismo teria sido o avô do autor de Mhudi, Selogilwe - que estava entre os tswana que, ao longo da década de 1830, assistiram à instalação de diferentes grupos missionários na região de Thaba Nchu, na região que anos mais tarde viria a ser conhecida como Estado Livre de Orange. No final daquela década, Selogilwe e sua família migraram para o sul, chegando à cidade de Philippolis, fundada pela London Missionary Society em 1823. Philippolis logo se tornaria um importante centro de referência também para outros grupos missionários que, ao longo dos anos, se estabeleceram nas cercanias. Foi nessa cidade que Selogilwe recebeu seu nome cristão - "Plaatje", que significa "plano" ou "chato" em holandês. ${ }^{3} \mathrm{O}$ nome fora dado a Selogilwe pelo

\footnotetext{
${ }^{2}$ Os rolong/baralong pertencem ao grupo dos falantes da língua tswana $e$ ocupam majoritariamente o território que hoje é conhecido como a Botswana.

${ }^{3}$ Na definição da pronúncia correta do nome "Plaatje" encontra-se também um espaço de negociação da língua afrikaans: brancos afrikaners defendem a pronúncia correta como sendo plaakie, enquanto que o nome também pode ser encontrado com a pronúncia plaatie - especialmente entre a população coloured. Nacionalistas afrikaners argumentam que os coloureds não têm um domínio preciso do afrikaans, corrompendo o idioma por não saberem pronunciar corretamente muitas palavras. Para mais informações sobre os coloureds e suas negociações político-identitárias, ver Salve (2012).
} 
fazendeiro griqua ${ }^{4}$ - falante do holandês - de quem ele arrendava terras, e fazia referência à "cabeça chata" de Selogilwe. Quando Solomon tinha cinco anos, sua família mudou-se de Boshof para a missão luterana de Pniel. Foi nesse ambiente que Plaatje passou boa parte de sua infância e sua adolescência, convivendo em meio a uma grande pluralidade cultural e linguística. Reconhecido como um dos estudantes mais aplicados da missão, Plaatje tornou-se também tutor dos estudantes mais novos, função que manteve até 1894 - quando ingressou no serviço público da Colônia do Cabo atuando como mensageiro na cidade de Kimberley. Nessa cidade, Plaatje conheceu a South African Improvement Society, ${ }^{5}$ tornando-se membro ativo nas reuniões que giravam em torno do aperfeiçoamento de leitura, interpretação e produção de textos em inglês.

Em 1898, Plaatje foi transferido para o serviço público da cidade de Mafeking, importante entroncamento ferroviário que conectava diversas cidades do interior sul-africano. Plaatje atuava agora como intérprete e tradutor na corte dos magistrados - $e$ foram essas as atividades que desempenhou com maior intensidade após a eclosão da Guerra Sul-Africana, ${ }^{6}$ em 1899. Ao final do conflito armado, no ano de 1902, Plaatje permaneceu em Mafeking. Com o incentivo de jornalistas e escritores com quem

${ }^{4}$ Os Griqua são pastoralistas, combinando em sua origem uma mistura dos khoikhoi e dos primeiros europeus que transitaram pelo território sul-africano, notadamente os funcionários da Companhia das Índias Orientais, e foram, a princípio, chamados de bastaards pelos colonos que ocuparam o território entre os séculos XVII e XVIII. Foi também ao longo do século XVIII que os Griqua se deslocaram ocupando territórios do que seria mais tarde conhecido como a República Bôer do Orange Free State (Saunders, Southey, Suttie, 2000:115117).

5 Criada em 1895, a South African Improvement Society tinha como principal objetivo tornar-se um grupo de referência para os sul-africanos negros que quisessem adquirir fluência na língua inglesa, partilhando a leitura de autores como Shakespeare e realizando exercícios de prática de pronúncia e escrita. Além disso, tratava-se também de difundir os valores que eram, então, atrelados à ideia de "civilidade" e "respeitabilidade" vinculados à língua e à cultura inglesa.

6 Também conhecida como Guerra Anglo-Bôer ou Guerra dos Bôeres. 
trabalhara durante a guerra, assumiu a redação do Koranta ea Becoana - "A Gazeta dos Bechuana", jornal bilíngue publicado em inglês e setswana. Retornou a Kimberley sete anos mais tarde, após o fechamento do Koranta; continuou, contudo, atrelado à carreira jornalística, agora como editor do também bilíngue Tsala ea Becoana ("O Amigo dos Bechuana"), que seria chamado, posteriormente, Tsala ea Batho - "O Amigo do Povo" (Willan, 1984:99-105).

O ano de 1902 trouxera ao território sul-africano não apenas o fim do conflito armado - com vitória britânica -, mas também a necessidade de consolidação de um projeto nacional capaz de oferecer maior estabilidade a uma região permeada por tensões étnicas e raciais que se aprofundavam com intensidade, colocando em risco a estabilidade da economia mineradora e dos investimentos do capitalismo imperialista britânico. Nesse cenário, ganhava força o projeto que desenhava uma nação sul-africana exclusivamente branca, e indivíduos como Sol Plaatje pertencentes a uma elite africana letrada $e$ cristã $e$ que se identificavam como subjects do império britânico - assistiam ao desmantelamento sistemático de sua presença no estado nacional em gestação.

O surgimento da União Sul Africana, em maio de 1910, foi acompanhado quase que imediatamente pelo endurecimento das legislações de caráter segregacionista. Nesse cenário, Plaatje ampliou seu status de figura de referência na luta pela chamada "causa nativa" ${ }^{7}$ em território sul-africano, e sua atuação foi fundamental na unificação das muitas vozes de contestação $e$ denúncia do regime de supremacia branca que começava a ganhar força também no campo legislativo. Em janeiro de 1912, durante a South African Native Convention, um grande número de chefias nativas reuniu-se com lideranças da imprensa, do

\footnotetext{
${ }^{7}$ Importante destacar que, quando o termo nativo/native aparecer empregado neste artigo, ele se refere ao termo utilizado pelas políticas elaboradas pela elite branca sul-africana entre a segunda metade do século XIX e as primeiras décadas do século XX.
} 
ensino e da política para fortalecer o projeto de criação de uma unidade política nacional que atuasse em oposição ao regime segregacionista. Nesse encontro nasceu o South African Native National Congress, ${ }^{8}$ que se propunha como um órgão disposto a intermediar as relações entre o recém-estabelecido governo nacional sul-africano e as populações nativas daquele território, atentando também para a promoção de políticas de desenvolvimento social, econômico, político e educacional nativo (Odendaal, 1984:274-275). John Dube foi eleito o primeiro presidente do SAANC - enquanto Plaatje, em contrapartida, foi indicado para atuar como primeiro secretário. ${ }^{9}$

O principal desafio enfrentado pelo SAANC apresentou-se já em junho de 1913 com a promulgação do Natives Land Act - lei que proibia a aquisição de terras por parte dos sul-africanos negros fora da área que a eles havia sido reservada (e que totalizava aproximadamente $7,5 \%$ do território nacional). Tratavase de uma lei ampla e repleta de pormenores que cerceavam as diferentes formas de relacionamento dos sul-africanos negros com a terra. Um comitê de emergência foi formado pelo SAANC, com a intenção de levar uma petição ao governo imperial: embora os britânicos tivessem adotado a prática da não interferência direta nos assuntos da recém-formada União Sul-Africana, ainda detinham o poder de vetar as leis que porventura julgassem prejudiciais aos interesses da jovem nação. Enquanto membros do SAANC organizavam-se em torno da elaboração da petição a ser apresentada em Londres e do levantamento de fundos que pudessem garantir a longa viagem e o período de permanência na capital imperial, Plaatje, por sua vez, partiu em viagem pelo

8 Referenciado, a partir deste ponto, pela sigla SANNC. Atente-se para o fato de que o SAANC viria a se tornar, alguns anos mais tarde, o African National Congress - ANC, de Nelson Mandela.

9 John Dube (1871-1946) é mais um dos exemplos expressivos de lideranças políticas negras sul-africanas que cresceram no espaço das missões cristãs e se tornaram parte de uma destacada elite intelectual, atuando especialmente entre as décadas finais do século XIX e o início do XX. Para mais informações sobre a negociação de uma memória política em torno de Dube, ver Barros (2012). 
interior sul-africano, registrando os reais impactos da nova legislação de terras nos cotidianos mais diversificados. Os relatos compilados nessa empreitada foram anexados à petição que uma delegação de cinco membros do SAANC - Plaatje incluído apresentou, sem sucesso, ao governo imperial em junho de 1914: às vésperas da eclosão da Primeira Guerra Mundial, não havia qualquer interesse em ampliar as tensões em que os britânicos se viam envolvidos.

Embora a experiência da delegação do SAANC em Londres tenha sido frustrante, portas pareciam se abrir para Plaatje - o jornalista não retornou com os companheiros de política para a União Sul Africana, permanecendo na capital do império até o ano de 1917, apoiado por uma rede de intelectuais interessados em dar visibilidade à condição do nativo sul-africano. Nesse período, os relatos compilados por Plaatje após a promulgação do Natives' Land Act de 1913 foram transformados no livro que se tornaria sua obra mais conhecida: Native Life in South Africa foi publicado pela primeira vez em 1916, alcançando grande sucesso e ampliando a rede de articulação política e literária de Plaatje para outras esferas de influência e diálogo que iam além daquela do poder imperial britânico. Os diálogos com W. E. B. Du Bois e o movimento negro norte-americano trouxeram novo fôlego à produção do literato sul-africano e, em 1920, Plaatje foi convidado para oferecer, em diversas cidades dos Estados Unidos e do Canadá, uma série de palestras sobre as condições de vida dos nativos na União Sul Africana (Vinson, 2012).

É no período compreendido entre 1917 e 1920 que se estima que Plaatje tenha escrito seu romance histórico Mhudi. Como a decepção com o projeto político britânico para o território sulafricano e a descoberta de novos diálogos na América do Norte afetaram a interpretação do literato sobre a "vida nativa" um século antes do surgimento da União Sul-Africana? 
2. Mhudi - An Epic of South African Native Life a Hundred Years Ago

Em seu prefácio à primeira edição de Mhudi, Sol Plaatje destacava que a obra havia sido escrita com dois objetivos: apresentar ao público leitor uma interpretação de aspectos fundamentais da "forma de pensar nativa" $e$, com o dinheiro arrecadado pelas vendas,

(...) reunir e imprimir (para escolas bantu) contos do folclore setswana que, com a disseminação das ideias europeias, estão sendo rapidamente esquecidos. Espera-se, portanto, deter esse processo, cultivando um amor pela literatura e pela arte [tswana] (...) (Plaatje, 1989 [1930]:11).

A preocupação de Plaatje com o resgate de aspectos da cultura tswana frente aos "avanços da cultura europeia" não era nova. Em 1916, mesmo ano da publicação de Native Life in South Africa, o primeiro secretário do SAANC havia publicado também uma compilação de aproximadamente setecentos provérbios tswana, apresentando suas traduções e identificando equivalentes europeus. ${ }^{10}$ Seu romance histórico parecia também dialogar com muitos dos temas que haviam preenchido Native Life in South Africa - a relação do nativo sul-africano com seu passado $e$ antepassados, $e$ as histórias de pertencimento a um local ou a um grupo, por exemplo. Na leitura dos relatos de viagem de Plaatje pelo interior sul-africano registrando os impactos do Natives Land Act no cotidiano de diversas pessoas, e no romance histórico Mhudi, no entanto, as ideias de pertencimento são marcadas por matizes distintos. Em Native Life in South Africa, a ideia de pertencimento é explorada como parte do discurso preocupado

${ }^{10}$ A obra recebeu o título Sechuana Proverbs, with Literal Translations and their European Equivalents. (Diane tsa Secoana le Maele a Sekgooa a a Dumalanang naco), e foi publicada em Londres pela Kegan Paul, Trench, Trübner \& Co. em 1916. Relatos indicam também que Plaatje trabalhava na compilação de lendas e contos da tradição popular tswana quando faleceu, no ano de 1932. 
em construir e divulgar formas de resistência às políticas de segregação que ganhavam espaço na União Sul-Africana. Contestava-se, afinal, a legislação promulgada em 1913, que rompia antigas relações de pertencimento dos nativos às terras que ocupavam. Em Mhudi, no entanto, a ideia de pertencer parece dialogar muito mais com um aspecto filosófico, quase um saber estar no mundo.

Escrito provavelmente entre os anos de 1917 e 1920 (Berrian, 181:335), o romance remete à primeira metade do século XIX, no período compreendido entre 1815 e 1838, e se passa em áreas que seriam, mais tarde, conhecidas como a colônia britânica de Natal e a República do Transvaal. Nesse período, essa região central do território sul-africano assistiu à chamada mfecane ou difaqanel lifaqane, ${ }^{11}$ termos resgatados pela historiografia para descrever o momento de intensas transformações que foram de uma ampla reordenação dos espaços ao surgimento de novas chefias que, no início do século XIX, se rebelaram contra o poder militarexpansionista de Shaka-Zulu - com especial destaque para os matabele, que assistiram à consolidação do poder de Mzilizaki, e para os sotho, sob o domínio de Moshoeshoe (Saunders, Southey, Suttie, 2000:172-173). Segundo a historiografia, muitos dos conflitos estabelecidos a partir da expansão zulu teriam criado um grande vazio demográfico na região, o que havia facilitado o deslocamento e a instalação de grupos bôeres que, a partir da década de 1830, abandonaram a Colônia do Cabo em virtude do aprofundamento das tensões com os britânicos - os quais viam como os propagadores de "leis injustas e opressoras". Esse deslocamento bôer pelo interior sul-africano ficou conhecido como

\footnotetext{
${ }^{11}$ Mfecane é o termo zulu para "esmagamento". Em Sotho, o termo difaqane, significa "martelada" e lifaqane, "migração forçada", cf. Saunders, Southey, Suttie (2000:172). Importante destacar que foi apenas a partir de 1960 que a historiografia passou a enfatizar o período da mfecane como um momento de expansão e consolidação de estados, indicando que interpretações que apontavam unicamente para a violência dos embates militares e para a ação de Shaka-Zulu estavam comprometidas, muitas vezes, com a legitimação de uma "conquista" branca daqueles territórios.
} 
the Great Trek, ou "a grande jornada", e passou a habitar um especial lugar na memória política e cultural dos bôeres, sendo resgatado com frequência para afirmar e reafirmar a superioridade bôer no território sul-africano.

No romance de Sol Plaatje, os personagens principais - RaThaga e a personagem que dá título ao romance, Mhudi - são barolongs. Importante destacar que, antes de iniciar sua narrativa, Plaatje abre espaço para apresentar os personagens de sua história: Mhudi é apresentada como "M'HUDI (a harvester, heroine of the tale (pron. Moody)", e Ra-Thaga - "(the bird mand), her husband" (Plaatje, 1989 [1930]:8). ${ }^{12}$ Atente-se para o fato de que Ra-Thaga é definido única e tão somente por seu papel em relação à Mhudi, a verdadeira heroína e protagonista do romance, como até mesmo a apresentação reforça; algo que parece peculiar quando levamos em consideração uma série de aspectos sobre a produção do romance: foi escrito no início do século XX, com reivindicações de reconstituir um período específico do século XIX; elaborado por um homem que carregava uma pesada bagagem de sua formação no espaço de ensino das missões cristãs - em que supostos "papéis de gênero" eram reforçados no estudo da Bíblia - e por um homem que partilhava de um código cultural que queria que os nativos "civilizados" reconhecessem que o espaço destinado para as mulheres era o ambiente doméstico, de proteção e gestação da família. ${ }^{13}$

\footnotetext{
${ }^{12}$ Os outros personagens apresentados por Plaatje são: "MZILIKAZI (the fermale mourner), King of the Matabele and Emperor of Central South Africa; UMNANDI (the sweet one), his favourite spouse; NO-MENTI, another spouse, bitterly jealous of UMNANDI; LANGA (sun), Crown Prince of the Matabele; GUBUZA, Commander-in-Chief of the Matabele Impis; QANDA, TABATA, SITONGA, DAMBUZA, DINGISWAYO, other warriors, and Uncles of Langa; TAUANA (Lion's whelp), Chief of the Barolong; MOROKA (Rainmaker), Chief of another Barolong clan; TAAIBOS, a Qoranna Chief; TON-QON, (his headman) a villain; POTGIETER, SAREL SILL-JAY, Boer Voortrekker Leaers; PHIL-JAY, a Noble Boer; PHIL-JUNE, VAN ZIJL, his friends; ANNTETJIE; PHIL-JAY'S FIANCÉE and sister to Zan Zjil" (Plaatje, 1989 [1930]:8).

${ }^{13} \mathrm{Um}$ dos principais esforços da atividade missionária na África austral foi combater o chamado "demônio da poligamia" entre os nativos, e também
} 
Ra-Thaga escapa do massacre que dizimou quase a totalidade de sua tribo, os thisidi barolong, e que fora conduzido por guerreiros matabele em uma vingança porque os barolong da tribo de Ra-Thaga, chefiados por Motshiwa, haviam matado dois coletores de impostos do rei dos matabele, Mzilikazi. Ra-Thaga $e$ Mhudi estão entre os poucos sobreviventes do massacre e, na fuga da devastação, apaixonam-se. Sozinhos no veld sul-africano, enfrentam as constantes ameaças do ambiente - de feras selvagens ao clima rigoroso que castigava a pele. O passar do tempo traz a descoberta de que outros tshidi barolong também haviam sobrevivido à destruição de sua vila, e que haviam se unido a um outro ramo dos barolong, os seleka barolong, da vila de Thaba Nchu, que acolheram os sobreviventes do massacre. Mhudi e Ra-Thaga são convidados a se unir ao grupo.

Em um determinado dia, um grupo de bôeres liderados por Sarel Cilliers chega a Thaba Nchu. Haviam partido da colônia do Cabo, território que se tornara hostil a eles após a ocupação sistemática dos colonos britânicos que julgavam bárbaros muitos dos hábitos dos bôeres - criticavam, especialmente, a manutenção da escravidão e acreditavam que os bôeres eram, na verdade, o melhor exemplo do risco de degeneração que o continente africano oferecia aos europeus. $\mathrm{O}$ primeiro contato entre esses bôeres que eram parte do movimento do Great Trek e os barolong fora relativamente amigável - os barolong avisaram aos voortrekkers $^{14}$ dos perigos que os matabele de Mzilikazi representavam para sua jornada e, em agradecimento, os bôeres asseguraram aos barolong que vingariam sua tribo massacrada.

Acompanhando o cotidiano dos matabele, descobrimos que Umnandi, a esposa favorita de Mzilikazi, havia desaparecido do vilarejo, deixando o chefe em completo estado de lamentação, ao

aproximar as mulheres - responsáveis, em grande medida, pela produção agrícola - de uma vida de "menor exposição" e centrada no recolhimento ao ambiente doméstico.

14 Termo em holandês que significa "aqueles que caminham à frente" ou "pioneiros". Tornou-se o termo usual para referenciar os bôeres que participaram do movimento do Great Trek a partir da década de 1830. 
mesmo tempo em que também vê frustrado o novo ataque organizado contra os barolong. Os bôeres, por outro lado, são atacados pelos homens de Mzilikazi e têm seu gado roubado e boa parte dos homens são assassinados. Os bôeres restantes são acolhidos pelos barolong em Thaba Nchu - e embora as relações entre os dois grupos étnicos tivesse se mostrado incialmente amigável, é possível perceber que alguma tensão ainda permeava o contato. É nesse momento que Ra-Thaga conhece De Villiers, um bôer que se torna seu amigo próximo. De Villiers aprende a língua de Ra-Thaga, o setswana, e ensina algo de seu idioma ${ }^{15}$ ao marido de Mhudi.

Algum tempo se passa até que os bôeres liderados por Potgieter e os barolong de Ra-Thaga decidam por um ataque contra os matabele, na esperança de acabar com qualquer tensão de que pudessem eles ser atacados por Mzilikazi. No acordo firmado, os bôeres concordavam que se estabeleceriam nas terras a leste do rio Molopo, deixando para os barolong as terras que eram ancestralmente suas. Enquanto a guerra eclode, Mhudi contrai malária e, nos sonhos da febre, vê Ra-Thaga sendo morto em batalha. Temendo por seu marido, decide abandonar Thaba Nchu e partir para juntar-se a ele no campo de batalha. Nessa jornada febril, Mhudi encontra Umnandi, a desaparecida esposa de Mzilikazi - que havia fugido após sofrer com as falsas acusações de adultério feitas pelas outras esposas do líder dos matabele, invejosas da atenção que a esposa favorita recebia e do poder que exercia sobre ele. As duas mulheres tornam-se amigas, separando-se apenas quando Umnandi retorna para Mzilikazi após

${ }^{15}$ Destaca-se que, até a metade do século XIX, a língua que viria a se tornar o afrikaans era definida por muitos como um "holandês distorcido $e$ incompreensível", que absorvera termos das línguas bantu e do inglês, francês, alemão e malaio. $\mathrm{O}$ afrikaans começa a ser pensado como idioma nacional nos anos iniciais do século XX - quando se quer consolidá-lo como língua dos homens brancos, atrelada também à própria constituição da identidade afrikaner. Nesse exercício, há um esforço de linguistas, jornalistas e literatos em "purificar" o afrikaans do que identificavam como "misturas que o haviam corrompido". Para mais detalhes, ver Polenis (1993). 
a derrota do chefe pelas forças unificadas entre bôeres $e$ barolongs. O retorno de Umnandi dá ao chefe matabele a certeza de que sua derrota fora, na verdade, um castigo por sua ambição, mas a alegria de ter sua esposa favorita de volta parece superar a infelicidade da derrota militar. Ao final da ameaça Matabele, Mhudi e Ra-Thaga retornam para Thaba Nchu, recebendo como presente dos amigos bôeres um vagão e gado. Nas páginas finais da narrativa, contudo, ressurge a lembrança de que nem todos os bôeres eram como aqueles que haviam se tornado amigos dos barolong:

Phil Jay havia ofendido seriamente as suscetibilidades de seu povo ao confraternizar abertamente com o casal negro e quando os boêres viram Mhudi e Ra-Thaga virarem as costas pela última vez ficaram felizes por descer a cortina sobre aquilo que consideravam vergonhoso (Plaatje, 1989 [1930]:199, tradução nossa). ${ }^{16}$

\section{Forjando uma heroína para a nação sul-africana}

Indícios levam a crer que o romance histórico de Sol Plaatje foi recebido com interesse pelo público - talvez não tanto por sua qualidade narrativa ou por ser um "romance rico e complexo" (Willan, 1984:361), mas por ser aquilo que alguns críticos ainda definiam como sendo o estilo narrativo "maravilhosamente bom, para um nativo" (Willan, 1984:361). A crítica mais incisiva à obra, contudo, afirmava que qualquer um que conhecesse a índole e o "temperamento" dos bôeres jamais acreditaria na possibilidade de uma história como aquela. O que parecia concentrar (e dividir) a atenção do público e dos críticos, no entanto, era o fato de Mhudi ser reivindicado como o primeiro romance escrito em inglês por um sul-africano nativo. Enquanto alguns defendiam que, ao escrever em inglês, Plaatje dava prova fundamental da

\footnotetext{
16 "Phil Jay grievously offended his people's susceptibilities by openly fraternising with the black couple, and when the Boers had seen the backs of Mhudi and RaThaga for the last time, they were glad to draw the curtian on what they regarded as a most disgraceful spectacle (...)" (Plaatje, 1989 [1930]:199).
} 
importância do esforço de "civilização" dos nativos, um outro grupo, por sua vez, lamentava que o autor não tivesse optado por produzir em tswana. Neste último grupo encontrava-se, por exemplo, o professor Clement Doke, da Universidade do Witwatersrand ${ }^{17}$ - que havia, inclusive, conseguido financiamento para as pesquisas de Plaatje sobre as tradições orais tswana, $e$ mostrava-se frustrado com o fato de Plaatje ter optado por não ampliar a literatura disponível em tswana, "infelizmente ainda muito escassa" (Green, 2008:329). ${ }^{18}$

Mas quem era, afinal, o leitor imaginado para o texto de Mhudi? Quem consumiria um romance que, a um só tempo, oferecia uma imagem do território sul-africano no período em que a ocupação britânica começava a ser mais sistemática $e$ retratava um momento de transição social, política e cultural que se desvelava no encontro de bôeres, britânicos e das populaçóes nativas, mas apresentava também uma reflexão sobre a "índole" de bôeres e barolong e criticava um injusto sistema de distribuição das terras sul-africanas? Dados sobre as taxas de alfabetização da União Sul Africana, resgatados por Tim Couzens, podem ajudar a entender quem teria sido o leitor idealizado por Sol Plaatje: em 1921, aproximadamente $10 \%$ da população negra era alfabetizada, enquanto que em 1931 essa porcentagem subiria para 12\% (Couzens, 1976:9). Nota-se, portanto, que o público leitor nativo era deveras reduzido. Plaatje atribuiu a gênese de seu romance histórico a um interesse pessoal: em 1899, durante o cerco a Mafeking, na Guerra Sul-Africana, teria convivido de maneira mais próxima com os barolong da região, conhecendo a história

\footnotetext{
${ }^{17}$ Clement Martin Doke (1893-1980) foi um linguista britânico que se especializou nas estruturas gramaticais das línguas bantu, produzindo vasto material entre gramáticas, dicionários e trabalhos comparativos com línguas europeias. Ver Herbert (1993).

${ }^{18}$ Interessante ressaltar que Vere Stent, antigo conhecido de Plaatje dos tempos em que atuaram juntos em Mafeking, ao celebrar a publicação de Mhudi destacava que "If Mr. Plaatje was a French subject ... they woulld fête him and make him a member of the Academie. In South Africa he is only a Native, and may not even ride a tram in the capital of the Union" (apud Willan, 1984:362).
} 
de tensão e rivalidade com os matabele. A partir daí, o autor dedicou-se ao esforço de reunir aspectos da história barolong que pudessem ajudar a compreender a origem $e$ a permanência dessas tensões. É curioso notar, entretanto, como elementos da história barolong - embora articuladores de parte do desenrolar da narrativa de Mhudi - acabam por não ser o principal foco de atenção do romance de Plaatje. Lembre-se, por exemplo, do que o próprio autor afirmara no prefácio de sua primeira edição: uma das intenções do livro era apresentar ao público leitor aspectos fundamentais da "forma de pensar nativa" (Plaatje, 1989 [1930]:11). Ora, qual seria o público que precisaria ser conduzido nesse questionar quase antropológico de "como pensam os nativos sul-africanos"? Outra questão se coloca: na recémconsolidada União Sul Africana, podemos imaginar que o livro possa ter sido acolhido entre o público anglófono com algum interesse ou curiosidade. Difícil imaginar, contudo, afrikaners em busca de um exemplar da narrativa que um nativo construíra a partir de um evento fundador da identidade bôer/afrikaner, o Great Trek - evento que ressaltava a suposta superioridade desse grupo étnico branco frente à hostilidade do território e das populações autóctones.

Essas observações levam a crer que Mhudi tenha sido idealizado para um público externo, imperial e anglófono provavelmente o mesmo que consumira Native Life in South Africa com grande interesse, em 1916. Brian Willan indica que após a publicação de Mhudi, Sol Plaatje encomendou à editora 250 cópias que ele mesmo cuidou de distribuir entre seus contatos na Inglaterra $e$ nos Estados Unidos, procurando editores interessados. O literato sul-africano chegou a escrever a W. E. B. Du Bois, perguntando sobre a possibilidade de publicar o romance histórico nos Estados Unidos, a exemplo do que acontecera com sua história da implementação da lei de terras na União Sul Africana; não existem, contudo, registros de uma eventual resposta de Du Bois. Plaatje também escreveu ao Dr. Robert Russa Moton, que fora indicado diretor do Tuskegee Institute após 
a morte de Booker Washington. ${ }^{19}$ Uma carta de resposta foi enviada por seu secretário, afirmando que:

Tenho dúvidas, contudo, se Mhudi encontraria na América a circulação que você esperaria que ele atingisse. É verdade que a literatura negra está em voga nesse momento, mas não a do tipo que seu livro representa. Não creio que alguma editora seria voluntária para colocá-lo em circulação, não tenho certeza se alguma das fundações iria patrociná-lo. Creio, no entanto, que o Dr. Moton ficaria feliz em contacta-las e ver o que poderia ser feito (apud Willan, 1984:365, tradução nossa). ${ }^{20}$

Embora nenhuma conclusão concreta sobre a possibilidade de publicação do romance na América do Norte tenha sido indicada pelo secretário do Dr. Moton, a carta retomava a

${ }^{19}$ Em sua visita à América do Norte, no início da década de 1920, Sol Plaatje visitou o Tuskegee Normal and Industrial Institute no Alabama (hoje a Tuskegee University). Fundado em 1881 por Booker T. Washington, o instituto era a materialização de uma proposta que defendia, como chave para a melhoria da condição do negro na América do Norte, a ampliação de oportunidades no ensino. Adotando o que muitos consideram uma política moderada $e$ conservadora, Washigton conseguiu apoio econômico para o empreendimento de Tuskegee, onde oferecia treinamento em uma industrial education - com atividades como a marcenaria ou novas técnicas de cultivo agrícola, as quais, acreditava, garantiriam o lugar do negro em uma sociedade que se ajustava ao final da escravidão, em 1863. Embora a postura de Washington tenha sido duramente criticada anos mais tarde, com o surgimento do movimento de luta por direitos civis, é fato que as propostas que desenvolveu no Tuskegee Normal and Industrial Institute muito se aproximavam aos ideais daquela primeira geração de liderança política nativa que se consolidava na União Sul Africana. A simpatia de Sol Plaatje pelo projeto de Booker T. Washington fez com que o autor de Mhudi enxergasse, no legado de Washington, o possível apoio e a chance de consolidar também seus projetos para os nativos sul-africanos (Vinson, 2012).

20 "I am doubtful, however, if Mhudi would find the circulation in America all that you would hope to achieve for it. It is true that Negro literature is in vogue at the present time, but not of the type which your book represents. I do not think any publisher would volunteer to issue it, but I am not sure that any of the Foundations would sponsor it. I think, however, that Dr. Moton would be glad to feel them out and see what could be done" (apud Willan, 1984:365). 
importante questão do interesse do público pela obra. Qual era, afinal, o tipo de negro literature que o livro que Sol Plaatje apresentava - e por que não era interessante ao mercado editorial norte-americano ou mesmo sul-africano? Seria apenas esse desinteresse editorial a razão do longo hiato que separou a finalização do romance, no início da década de 1920, de sua publicação, em 1930?

Não se pode dizer que Plaatje não insistiu em tentativas de levar o texto a público logo após sua finalização. Ainda em sua estadia na América do Norte, enviou o manuscrito às principais editoras dos Estados Unidos - Macmillan, Harper Brothers, Scribners e Harcourt, recebendo negativas de todas elas. Em Londres, em 1922, a Allen \& Unwin aceitou publicar Mhudidesde que Plaatje garantisse $£ 75$ para a empreitada inicial. Sem o dinheiro e sem ter como levantar essa quantia, o sul-africano procurou outras editoras que não cobrassem o subsídio, mas não obteve sucesso. Novas tentativas parecem ter ficado em suspenso após o retorno de Plaatje a União Sul-Africana - sabe-se, no entanto, que em novembro de 1929 ele escreveu à Lovedale Press perguntando se haveria interesse na publicação do manuscrito $e$ também de algumas peças de Shakespeare traduzidas para o tswana (Willan, 2015:1334). Foi a partir desse mesmo ano que a Lovedale Press passou por profundas transformações com a chegada do reverendo Robert H. W. Shepherd. Estudioso do papel da atuação missionária na publicação $e$ na circulação de material literário para os africanos, ${ }^{21} \mathrm{o}$ jovem reverendo acreditava que a exposição constante dos nativos a materiais que julgava permeados por elementos não cristãos e até mesmo antirreligiosos colocava em risco o empreendimento das escolas missionárias. Cabia às missões reconhecer que o novo momento do território sul-africano demandava também uma nova postura de suas

\footnotetext{
${ }^{21} \mathrm{O}$ reverendo publicaria, anos mais tarde, o livro Lovedale and the Literature for the Bantu - baseado na tese de doutorado em literatura que defendeu na Universidade do Witwatersrand. O livro foi publicado pela Lovedale Press em 1945.
} 
atividades - uma nova postura que passava também por tornar vasta e acessível uma literatura "de boa qualidade" para os nativos. Nas décadas seguintes, Shepherd envolveu-se pessoalmente em projetos de divulgação literária que iam desde "bibliotecas móveis" que se deslocavam pelo interior sul-africano até cursos de formação de escritores africanos (Peires, 1979:156). O que Shepherd teria visto em Mhudi para considerar o romance histórico de Sol Plaatje uma obra que se encaixava na ideia de "boa literatura para africanos"? ${ }^{22}$ Essa resposta passa, em muitos sentidos, pela representação de moralidade que marca a protagonista do romance - e pela concepção de um lugar e um papel para a mulher africana no jovem estado nacional sulafricano.

Sabe-se que Plaatje fez diversas alterações em seu manuscrito original, ${ }^{23}$ reduzindo capítulos e também parte da

${ }^{22}$ Destaque-se que, embora a Lovedale Press tenha sinalizado seu interesse na publicação de Mhudi, nada foi mencionado quanto à possibilidade de publicação das peças de Shakespeare que Plaatje havia traduzido do inglês para o tswana (Willan, 2015:1335). Essa informação torna-se curiosa quando lembramos das acusações sofridas por Plaatje após a publicação de Mhudi - especialmente aquelas que diziam que o autor deveria ter escrito seu romance histórico em Tswana, e não em inglês. Ora, se havia a possibilidade de, como muitos pediam, ampliar a disponibilidade de obras literárias nas línguas bantas, o que teria levado a Lovedale Press a evitar a publicação das peças de Shakespeare? É provável que acadêmicos como o professor Clement Doke, da Universidade do Witwatersrand, e uma editora atrelada ao esforço missionário na África austral tivessem pontos de vista distintos quanto à melhor forma de consumo da literatura por parte dos nativos. Lembre-se, ademais, que a editora missionária guardava compromissos com o esforço de "civilizar" os nativos - esforço que passava, de maneira incontornável, pelo aprendizado de línguas europeias especialmente o inglês.

${ }^{23}$ Diversos debates têm sido travados, nas últimas quatro décadas, sobre as motivações dessas alterações no texto original de Mhudi. De maneira breve, podemos indicar o artigo clássico "'Printers' and Other Devils: The Texts of Sol Plaatje's Mhudi', de Tim Couzens e Stephen Gray - publicado em 1978, que influenciou toda uma geração de novos pesquisadores a refletir sobre o provável poder de censura que a editora missionária teria sobre os textos por ela publicados. Mais recentemente, Brian Willian - autor da biografia de Sol Plaatje que contou com maior fôlego documental até agora - indicou que a influência do 
multiplicidade de narradores do romance - traço que indicava, de certa forma, elementos da oralidade na transposição da história dos barolong para sua versão escrita. Tim Couzens e Stephen Gray apontam que uma das alterações perceptíveis entre o manuscrito original de Mhudi e a edição publicada pela Lovedale Press foi também um processo de transformação da narrativa para torná-la mais agradável, algo que teria acabado por emascular o romance (Couzens; Gray, 1978). É fato que Mhudi foi influenciado também pela literatura imperialista anglófona em destaque no período - como Rider Haggard, por exemplo. Mas Plaatje, na verdade, foi além de suas influências e deslocou o foco do romance - do típico romance histórico que se poderia esperar nas décadas iniciais do século $\mathrm{XX}$ - de uma esperada figura masculina para Mhudi, sua protagonista. $\mathrm{O}$ arquetípico herói que se poderia esperar para o romance que se reivindica "épico" é apresentado na figura de uma mulher. É ela quem dá nome ao épico, que envolve e toca todos os personagens da trama, quem reorganiza um mundo em transformação. Soa estranho, portanto, esbarrar em leituras que reclamam que supostas edições do texto teriam acabado por retirar a virilidade da narrativa - quando na verdade a proposta do romance é justamente a de apresentar outro protagonismo para um evento que muitos queriam indicar como a gênese da nação sul-africana. O épico de Plaatje, assim como sua nação imaginada, torna-se possivel apenas no feminino.

Sabe-se que boa parte da obra política e literária de Plaatje foi influenciada por aquela da literata e feminista Olive Schreiner uma das pioneiras a pensar a construção do estado nacional sulafricano nas décadas finais do século XIX. Schreiner destacava constantemente em seus escritos a importância da mulher na construção da nacionalidade sul-africana - e, em especial, a importância da mulher bôer, quem a autora considerava o

argumento de Couzens e Gray foi deveras prejudicial a toda uma geração de pesquisadores, uma vez que teriam iniciado suas pesquisas já naturalizando um suposto poder de censura exercido pelos missionários. Além disso, Willan indica que o argumento tece uma imagem de subserviência do literato que parece não condizente com sua biografia (Willan, 2015). 
exemplo de retidão moral necessário para a consolidação do estado nacional. Era também a mulher que daria origem a um novo homem - a uma nova humanidade - naquele extremo sul do continente africano. O tempo traria a inevitável união entre ingleses e bôeres, consolidando a existência dos sul-africanos brancos da nação desejada. É impossível, em muitos aspectos, não comparar a trajetória de Mhudi à experiência de Schreiner na publicação de seu The Story of an African Farm, em 1883. Com um texto que apresentava o cotidiano de uma fazenda no interior do território sul-africano na segunda metade do século XIX, a literata parecia criar em sua personagem principal, Lyndall, um reflexo da nação que esperava - tolerante e em diálogo com nativos, bôeres e toda a variedade de figuras humanas que permeavam a trama, numa alusão à multiplicidade da própria sociedade sul-africana. ${ }^{24} \mathrm{~A}$ morte de Lyndall, ao final do texto, reforça a ideia de que não havia espaço para uma personagem como aquela no mundo de The Story of an African Farm - assim como parecia não haver espaço para uma nação forjada na tolerância e diálogo, no século XIX. Enquanto isso, nas décadas iniciais do século XX, Sol Plaatje idealizava uma gênese da nação sul-africana que passava pela agência e pelo protagonismo de Mhudi - sua nação era também feminina. Diferentemente de Lyndall, Mhudi não poderia encontrar a morte ao final da narrativa; em sua permanência estava a esperança necessária para resistir à opressão da legislação segregacionista que ganhava força.

Ao iniciar seu romance histórico com um resgate dos eventos decorrentes da mfecane, Sol Plaatje resgata também uma história de povos desalojados e em deslocamento, precisando

\footnotetext{
${ }^{24}$ Para mais informações sobre a produção literária de Olive Schreiner e seu papel político na sociedade imperial, ver McClintock (2010). Para uma análise mais detalhada do romance The Story of an African Farm, ver Gomes (2013).
} 
reapropriar seus espaços e identidades. O autor retorna cem anos no tempo para resgatar como os matabele haviam desalojado $e$ devastado as terras barolong e como esse grupo tswana, mais tarde - em uma aliança com os bôeres que se deslocavam da Colônia do Cabo rumo ao interior -, havia se vingado dos matabele (Voss apud Willan, 1984:18). Nesse sentido, podemos identificar a heroína da narrativa, Mhudi, seu companheiro, RaThaga, e os poucos barolong restantes em seu grupo após o embate com os Matabele, como representantes dos muitos nativos desalojados por conta da implementação do Natives Land Act, em 1913 - lembre-se, por exemplo, da sensação de abandono e deslocamento transmitida pelos personagens ao encontrarem destruída sua vila, Kunana, após o incêndio perpetrado pelos homens de Mzilikazi. Sensação próxima, provavelmente, a de Plaatje, ao perceber-se politicamente abandonado por uma política imperial britânica dona de ideais que ele, por tanto tempo, defendera como o único caminho para salvação do nativo sulafricano. Mhudi é, sim, uma história de deslocamentos forçados e de deslocados tentando a reconstrução, e seus protagonistas não são apenas os barolong das páginas do romance, mas também homens e mulheres como Plaatje, que tentavam se ajustar ao novo cenário político sul-africano.

Mhudi e Ra-Thaga, os únicos a serem nomeados na narrativa entre os barolong que sobreviveram ao massacre conduzido pelos Matabele de Mzilikazi, representam, em verdade, as possibilidades de ajuste às novas condições que se colocam aos nativos sul-africanos. E, embora o romance destaque essas novas condições se desenrolando na década de 1830, parte dos leitores que segurassem o livro após sua publicação, em 1930, poderia acreditar-se contemplando narrativas de deslocamento que poderiam ser contemporâneas à leitura. A. E. Voss defende, na verdade, que Mhudi foi uma forma encontrada por Plaatje para resgatar as raízes do trauma que ganhava espaço na sociedade sul-africana e permeava a experiência dos nativos - um argumento que pode ser validado, por exemplo, ao lembrarmos que, apesar de toda a violência perpetrada pelos Matebele ao 
longo da narrativa, Plaatje não se permite narrar a nação derrotada: como indica Anthony Chennels, "Ao invés disso, vemos Mzilikazi e seu povo nas florestas do que hoje é a Botswana, a centenas de milhas ao norte da cena, de sua tirania e de sua derrota, reconstruindo a si mesmos novamente como uma nação" (Chennels, 1997:39). ${ }^{25}$

Enquanto isso, é interessante destacar como Plaatje tece nova inversão de concepções pré-estabelecidas. Se o autor de Mhudi optara por descrever Ra-Thaga unicamente como marido da protagonista da narrativa, parecia também relembrar aos afrikaners algumas condições do Great Trek que aparentemente se queriam esquecidas. É o caso do diálogo de Sarel Siljay, um dos bôeres que se deslocava pelo território, com o chefe Moroka dos barolong:

"Mas", perguntou o chefe Moroka, "vocês não poderiam adorar a Deus no sul do rio Orange?"

"Poderíamos", respondeu Siljay, "mas a opressão não conduz à piedade. Buscamos liberdade. As leis inglesas do Cabo não são justas conosco".

"Nós barolong sempre ouvimos dizer que desde Davi e Salomão nenhum outro rei governou de maneira tão justa quanto o rei George da Inglaterra."

"Pode ser que sim", respondeu o líder bôer, "mas existem sempre dois pontos de vista. O ponto de vista daquele que governa nem sempre é o ponto de vista do governado. Nós bôeres estamos cansados de reis e governantes estrangeiros. Queremos um só governante, que é Deus, nosso criador. Nenhum homem ou mulher pode governar outro" (Plaatje, 1989 [1930]:87-88, tradução nossa). ${ }^{26}$

25 "Instead we see Mzilikazi and his people in the forests of what is modern-day Botswana, hundreds of miles north of the scene, both of their tyranny and their defeat, reconstructing themselves again as a nation" (Chennels, 1997:39).

26 "But", asked Chief Moroka, "could you not worship God on the South of the Orange River?", "We could", replied Siljay, "but oppression is not conductive to piety. We are after freedom. The English laws of the Cape are not fair to us". "We Barolong have always heard that, since David and Solomon, no king has ruled so justly as King George of England". "It may be so", replied the Boer leader, "but 
Em 1930, em meio a um processo de consolidação da legislação segregacionista na União Sul Africana, encontramos no romance de Sol Plaatje um personagem branco, um bôer, recriminando a imposição de leis (definidas como "injustas") e a opressão de seu povo. Podemos pensar que parte dos problemas enfrentados pelo literato sul-africano em encontrar uma editora interessada em publicar seu livro pudesse estar atrelada a essa narrativa que tocava em uma memória sensivel aos afrikaners - o Great Trek que, além de tudo, em um movimento duplamente ousado, surgia reconstruído no campo literário por um sul africano negro.

Aqui, a escolha de Plaatje por uma protagonista feminina para seu romance histórico torna-se novamente alvo de destaque. Mhudi, uma mulher, africana, negra, está no cerne de um dos principais eventos históricos resgatados pelo romance - os impactos do Great Trek no território e nas populações sulafricanas. É Mhudi que, no desenrolar da narrativa, é obrigada a abandonar as terras de sua ancestralidade $e$ a vida como conhecia. Na jornada em busca de um novo espaço para se estabelecer, constrói uma personalidade marcada pela resiliência $e$ independência - é chamada de "o berço de sua raça" e torna possível um novo começo para seu povo. Em um momento em que milhões de africanos sofriam os impactos de terem sido diretamente afetados por leis como o Natives Land Act, de 1913, Sol Plaatje criava, na literatura, cenários possíveis de resistência $e$ sobrevivência para aqueles que se viam subitamente privados de um dos referenciais primeiros da cultura africana: a terra.

É também a figura de Mhudi que resgata o passado e a noção de pertencimento de Ra-Thaga quando, acreditando não existirem mais membros de Kunana vivos após o massacre do vilarejo, encontra Mhudi:

there are always two points of view. The point of view of the ruler is not always the view point of the ruled. We Boers are tired of foreign kings and rulers. We only want one ruler and that is God, our Creator. No man or woman can rule another" (Plaatje, 1989 [1930]:87-88). 
Até conhecer você, eu não acreditava que existisse outro de nossa tribo, e nunca esperei ouvir nossa língua ser falada novamente. Ao ver você, não acreditei que fosse uma barolong. Mas de qualquer forma ficamos nós dois vivos para contar a história - mas, para quem? Ah, sim, para quem? (Plaatje, 1989 [1930]:78, tradução nossa). ${ }^{27}$

Sol Plaatje concentra o poder de sua narrativa na figura que, na África do Sul das primeiras décadas do século XX, era aquela que mais facilmente poderia ser imaginada sem Voz no cenário político-social: uma mulher negra. Outras figuras de poder da narrativa também são mulheres: a rainha Umnandi dos Ndebele e a jovem bôer Annetje. Há, sim, personagens masculinos fortes em Mhudi - o herói Ra-Thaga, companheiro da protagonista, o rei Mzilikazi, o bôer Phil Jay. Esses homens, no entanto, têm seu poder na narrativa consolidado majoritariamente a partir das relações que estabelecem com mulheres.

$\mathrm{O}$ romance histórico Mhudi pode, nesse sentido, ser compreendido também como uma primeira tentativa de inserir, de resgatar, o sul-africano negro nas narrativas que construíram a ideia de nação entre os séculos XIX e XX - e não como um capítulo à parte nas relações estabelecidas entre os grupos brancos, mas como um agente fundamental e inevitável. Criava também algo que poderia ser visto como extremamente interessante para as imprensas missionárias: um modelo do comportamento sócio-moral da mulher negra. Kathy Eales indica como os deslocamentos impostos pelos fluxos migratórios da mão de obra na indústria mineradora acabaram por transformar em um problema a presença da mulher negra nos grandes centros urbanos - sem espaço na mineração, aquelas que acompanhavam seus familiares e companheiros acabavam por buscar outras formas de trabalho remunerado num ambiente que se

27 "Until I met you, I did not believe that another of our tribe existed, and I had never expected to hear our language spoken again. On seeing you I did not believe that you were a Barolong. But it turns out that two of us, at any rate, are left alive to tell the story, but - to whom? Ah yes, to whom?' (Plaatje, 1989 [1930]:78). 
estabelecera fundamentalmente como masculino: na região mineradora do Rand sul-africano, por exemplo, boa parte de atividades da esfera doméstica que seriam imediatamente atreladas, naquela época, à figura feminina - dos jardins às cozinhas -, eram na verdade desempenhadas por homens negros - os famosos houseboys. Nos circuitos brancos, propagava-se a ideia de que mulheres negras não eram "confiáveis" e que eram propensas à "imoralidade", tendo espaço apenas na prostituição (Eales, 1988:1-2).

Dirigindo seu romance a um grupo branco e anglófono, Plaatje dialogava também com um outro elemento fundamental do imperialismo britânico: aquele que Anne McClintock define como o "culto vitoriano ao doméstico" (McClintock, 2010:43-121). Mhudi é devota a seu marido e ao espaço em que constituem um lar; está distanciada, portanto, da ideia da mulher africana que transita entre a selvageria e a sensualidade - a como boa parte das mulheres que habitam a ficção de Rider Haggard, por exemplo - $e$ aproxima-se dos padrões que enaltecem a figura feminina que zela por sua família. Podemos pensar que Sol Plaatje estava abrindo caminhos para que o público britânico tivesse acesso a uma nova imagem da mulher negra sul-africana. E ao divulgar essa narrativa, a Lovedale Press reafirmava a importância de seu papel no processo de oferecer a "civilização" aos nativos.

Mhudi narra processos de reordenamento não apenas territoriais - como a reconstrução da vila de Kunana após o ataque dos matabele de Mzilikazi, ou a ocupação de um novo território pelos bôeres que se deslocam no Great Trek -, mas também o estabelecimento de novas organizações políticas $e$ pessoais, de repensar alianças que, no início do século $\mathrm{XX}$, mostram-se frágeis e inviáveis. Frustrado com o modelo das políticas britânicas oferecidas para os sul-africanos negros $e$ também com a incapacidade do South African Native National Congress de constituir-se como uma referência na articulação de 
resistência ao avanço segregacionista, é provável que Plaatje guardasse também a desilusão com o modelo de vida ao qual fora apresentado no espaço das missões cristãs - espaços de propagação dos chamados "ideais da vida civilizada". Quando lembramos que o lucro obtido com a venda do romance histórico seria destinado a programas de resgate de aspectos da tradição tswana junto a crianças em idade escolar, notamos que Plaatje projeta o resgate de aspectos ancestrais de uma cultura que se via ameaçada de desaparecer em meio à imposição e à adoração de modelos europeus idealizados e que de pouco haviam adiantado aos sul-africanos negros.

Melancólico, o texto de Mhudi é marcado pelo momento político que a ele dá origem: aquele em que práticas segregacionistas enraizadas no território sul-africano desde os primeiros séculos da presença europeia ganhavam o peso da legalidade, saindo de espaços localizados e tornando-se política nacional. Ao leitor, fica a consciência do que as décadas seguintes trouxeram para os sul-africanos apesar da narrativa idealizada de reconstrução de um passado que se queria recomeço.

\section{Referências bibliográficas}

ALVERSON, Hoyt. Mind in the Heart of Darkness. Value and self-identity among the Tswana of Southern Africa. New Haven, London, Yale University Press, 1978.

AtTwell, David. Rewriting Modernity. Studies in Black South African Literary History. Athens, Ohio University Press, 2005.

AzEvedo, Aina Guimarães. Conquistas Cosmológicas: pessoa, casa e casamento entre os Khubeka de Kwazulu-Natal e Guateng. Tese (Doutorado em Antropologia Social), Universidade de Brasília, 2013.

BARros, Antonio Evaldo Almeida. As faces de John Dube: memória, história e nação na África do Sul. Tese (Doutorado em Estudos Étnicos e Africanos), Programa Multidisciplinar de Pós-Graduação em Estudos Étnicos e Africanos, Universidade Federal da Bahia, Salvador, 2012. 
BeInART, William; DuBOw, Saul (org). Segregation and Apartheid in twentieth-century South Africa. London: Routledge, 2005.

BERRIAN, Brenda F. South African Literature. Canadian Journal of African Studies/Revue Canadienne des Études Africaines, vol. 15, $\mathrm{n}^{\circ}$ 2, 1981, pp.335-336.

BoEHMER, Elleke. Empire, the National, and the Postcolonial, 18101920. Resistance in Interaction. Oxford, Oxford University Press, 2002.

BORGES, Antonádia. Explorando a noção de etnografia popular: comparações e transformações a partir dos casos das cidades-satélites brasileiras e das townships sul-africanas. Cuadernos de Antropología Social, n² 29, Buenos Aires, 2009, pp.23-42.

CHENNELls, Anthony. Plotting South African History: Narrative in Sol Plaatje's "Mhudi". English in Africa, vol. 24, nº 1, 1997, pp.37-58.

CHRISMAN, Laura. Rereading the Imperial Romance: British Imperialism and South African Resistance in Haggard, Schreiner, and Plaatje. Oxford, Oxford University Press, 2000.

COMAROFF, John; COMAROFF, Jean. Of Revelation and Revolution. Chicago, University of Chicago Press, 1991, 1997 [2 vol.].

Couzens, Tim. A Short History of The World (and other South African Newspapers). African Studies Seminar Paper, Joanesburgo, University of the Witwatersrand, African Studes Institute, junho de 1976.

; GRAY, Stephen. "Printers" and Other Devils: The Texts of Sol T. Plaatje's Mhudi. Research in African Literatures, vol. 9, n² 2, 1978, pp.198-215.

DICK, Archie L. Building a Nation of Readers? Women's Organizations and the Politics of Reading in South Africa, 1900-1914. Historia, $\mathrm{n}^{\circ}$ 49, vol. 2, nov. 2004, pp.23-44

DISTILLER, Natasha. Shakespeare and the coconuts. On post-apartheid South African culture. Johannesburg, Wits Universtiy Press, 2012.

EALES, Kathy. "Good Girls" vs "Bad Girls". Agenda: Empowering Women for Gender Equality, n 4, 1989, pp.1-22. 
GOMES, Raquel G. A. Uma feminista na contramão do colonialismo. Olive Schreiner, literatura e a construção da nação sul africana, 18801902. São Paulo, Annablume/Fapesp, 2013.

GREEN, Michael. Translating the Nation: From Plaatje to Mpe. Journal of Southern African Studies, vol. 34, n 2, 2008, pp.325-342.

HERBERT, Robert K. (ed). Not wit one mouth. Continuity and change in Southern African Language Studies. African Studies, vol. 52, n 2 , 1993.

HoOPER, Myrtle. Two Sides of Empire: Heart of Darkness and Mhudi. The Conradian, vol. 17, n 1, 1992, pp.37-43.

. Nation, Narration and Cultural Translation: Heart of Darkness and Mhudi. Alternation, vol. 4, n 2, 1997, pp.103-113.

MARX, Anthony. Making race and nation. Cambridge, Cambridge University Press, 1998.

MCCLINTOCK, Anne. Couro Imperial. Raça, gênero e sexualidade no embate colonial. Campinas, Editora da Unicamp, 2010.

MoUTiNHO, Laura. "Raça", sexualidade e gênero na construção da identidade nacional: uma comparação entre Brasil e África do Sul. cadernos pagu (23), Campinas, Núcleo de Estudos de GêneroPagu/Unicamp, julho-dezembro de 2004, pp.55-88.

MZAMANE, Mbulelo Vizikhungo. Colonial and Imperial Themes in South African Literature 1820-1930. The Yearbook of English Studies, vol. 13, Colonial and Imperial Themes Special Number, 1983, pp.181195.

OdendAal, André. Black protest politics in South Africa to 1912. New Jersey, Barnes \& Noble Books, 1984.

PEIRES, Jeffrey. The Lovedale Press: Literature for the Bantu Revisited. History in Africa, vol. 6, 1979, pp.155-175.

PlaAtJE, Sol. Native Life in South Africa. Cape Town, Glavin \& Salves, 1982 [1916].

. Mhudi - An Epic of South African Native Life a Hundred Years Ago. Pretoria, Ad. Donker Publisher, 1989 [1930]. 
PonelIS, Fritz. The Development of Afrikaans. Frankfurt, Peter Lang, 1993.

ROSA, Marcelo. Reforma agrária e land reform: movimentos sociais e o sentido de ser um sem-terra no Brasil e na África do Sul. Caderno CRH, vol. 25, n 64, janeiro-abril, 2012, pp.99-114.

SALVE, Giovani Grillo de. Uma história de traição: um projeto assimilacionista coloured na Cidade do Cabo, 1906-1910. Dissertação (Mestrado em História), Universidade Estadual de Campinas, 2012.

SAMIN, Richard. Religion and Cultural Tutelage: The Lovedale Press and the Making of African Literature. In: MolumELI, Jamary; PRUM, Michel. Missionary Work in Africa in Eugène Casalis's Time and Beyond. Cambridge, Cambridge University Press, 2015, pp.79-88.

STANLEY, Liz; DAMPIER, Helen. Cultural Entrepeneurs: Proto-Nationalism and Women's Testimony Writings: From the South African War to 1940. Journal of Southern African Studies, vol. 33, $\mathrm{n}^{\circ} 3,2007$, pp.501-419.

SAUNDERS, Christopher; SouTHEY, Nicholas Southey; SuTTIE, Mary-Lynn. African Historical Dictionaries, n 78 - "Historical Dictionary of South Africa". Lanham, Maryland, London, The Scarecrow Press, 2000.

VALE, Maíra Cavalcanti. "Este país é cheio de apartheid", diálogos com mulheres sul-africanas na província de KwaZulu-Natal. cadernos pagu (45), Campinas, Núcleo de Estudos de Gênero-Pagu/Unicamp, julhodezembro de 2015, pp.51-78.

VINSON, Robert Trent. The Americans are coming! Dreams of African American Liberation in Segregationist South Africa. Athens, Ohio University Press, 2012.

Willan, Brian. Sol Plaatje - South African Nationalist, 1876-1932. Berkley/Los Angeles, University of California Press, 1984.

. What "Other Devils"? The Texts of Sol T. Plaatje's Mhudi Revisited. Journal of Southern African Studies, vol. 41, n 6, 2015, pp.1331-1347. 